\title{
OS ASSIM CHAMADOS "CORREDORES HUMANITÁRIOS" E O POSSÍVEL PAPEL DA SOCIEDADE CIVIL NAS POLÍTICAS DE REFÚGIO E MIGRAÇÃO REGULAR
}

\author{
The "humanitarian corridors" and the possible role of civil society in \\ asylum and regular immigration policy
}

Paolo Morozzo Della Rocca*

\begin{abstract}
Resumo. No passado, o principal problema dos refugiados e dos migrantes estava na superação das fronteiras. Hoje, no entanto, para a maior parte dos migrantes as verdadeiras fronteiras são os consulados, onde se torna cada vez mais difícil conseguir o visto. De fato, somente àqueles que não têm direito de permanecer na Europa se autoriza obter o visto de turista. Por outro lado, aqueles que terão direito ao refúgio não podem solicitar o visto de turista e por isso são obrigados a se entregar às organizações de tráfico de migrantes (smuggling). O projeto "corredores humanitários" oferece canais legais de migração para a Europa para aqueles que têm direito à proteção. O projeto é implementado e totalmente financiado por entidades privadas. Proporcionar rotas de ingresso regular aos solicitantes de refúgio e àqueles que já possuem redes familiares em países europeus não é a única solução possível, mas certamente é uma boa alternativa para gerenciar de forma humana e eficiente as migrações para o continente europeu.
\end{abstract}

Palavras-chave: solicitantes de refúgio, corredores humanitários, sponsorship, imigração irregular.

Abstract. Once, the main problem for migrants and asylum-seekers was the refoulement at the borders. Today instead, for many more migrants the real borders are the consulates where it's always more difficult to get a visa. In fact, only those who don't have the right to remain in Europe are allowed to obtain a visa (as tourist). Otherwise, those who will be granted asylum don't have right to apply for a visa, then they needs to fall in the smuggling organizations. The "humanitarian corridors" project offers legal ways to travel to Europe to those who have the right to protection. The project is realized and fully funded by private sponsors. To offer legal ways to asylum seekers and those who already have family ties in a European country is not the only answer, but it is certainly a good answer.

Keywords: asylum seekers, humanitarian corridors, sponsorship, irregular immigration.

\footnotetext{
* Professor de direito na Universidade de Urbino. Roma, Itália.
} 


\section{Notas introdutórias ${ }^{1}$}

No direito internacional, os Procedimentos de Entrada Protegida (PEPs) são aqueles que permitem às pessoas que precisam de proteção chegar ao país de destino em condições de plena legalidade e segurança. Podem compreender, de forma específica, a análise do pedido de proteção internacional no Consulado do país de destino localizado no país terceiro (no país de origem ou de presença temporária do solicitante). Em caso de resultado positivo, haverá a emissão de um visto ou, então, a imediata concessão de um "visto por razões humanitárias", que será, em seguida, definitivamente examinado no país de destino.

Nesta segunda modalidade se inserem dois Protocolos de Entendimento assinados, na Itália, entre o Ministério do Interior e o Ministério dos Negócios Estrangeiros, de um lado, e algumas associações de cunho religioso do outro (Federação das Igrejas Evangélicas na Itália e Tavola Valdese, Comunidade de Santo Egídio, Conferência Episcopal Italiana). Um terceiro Protocolo análogo foi assinado no Eliseu entre o governo da França e as entidades promotoras (Conferência dos Bispos da França, a Federação Protestante da França e a Comunidade de Sant'Egidio) ${ }^{2}$.

Os Protocolos preveem, até dezembro de 2017, a entrada protegida na Itália de 1.500 refugiados do Líbano e da Etiópia e, na França, de 500 refugiados do Líbano. No entanto, os promotores da iniciativa, incentivados pelo êxito do projeto, estão pedindo um prolongamento da duração das ações.

A admissão dos beneficiários e seu deslocamento para a Europa são geridos localmente pelas organizações promotoras, que são responsáveis pela transferência para a Itália e para a França, bem como pelo acolhimento nos contextos de suas redes locais de solidariedade.

O projeto é, portanto, autofinanciado e gerenciado pelas organizações promotoras em todas as fases, independentemente dos tempos de acolhimento, que os promotores calculam em pelo menos um ano. São planejadas atividades de formação e integração, inclusive no que diz respeito à inserção no mundo de trabalho, não sendo considerados de forma rígida os prazos previamente estabelecidos para a saída das estruturas de acolhimento.

Em uma primeira aproximação, o projeto de "abertura de corredores humanitários" constitui um modelo de sponsorship destinado a reassentar potenciais titulares de proteção internacional. Esta ênfase na "potencialidade"

\footnotetext{
Artigo traduzido do italiano pela equipe do CSEM.

2 O primeiro Protocolo foi assinado no dia 15 de dezembro de 2015; o segundo no dia 12 de janeiro de 2017; e o terceiro no dia 14 de março de 2017. Estão sendo realizados contatos para a adesão de outros países ao projeto.
} 
- no lugar do reconhecimento efetivo ou prima facie do direito à proteção internacional - é uma das peculiaridades do projeto, que também está voltado para a ampliação em sentido humanitário do leque dos possíveis beneficiários.

\section{Fluxos migratórios e crises humanitárias}

Sabe-se que a grande maioria dos refugiados permanece, hoje, nos assim chamados países de primeiro asilo (para os sírios, por exemplo, a Turquia, o Líbano, a Jordânia e o Egito) com pouca ou nenhuma possibilidade de inclusão social.

Ainda assim, de acordo com as linhas de ação do Alto Comissário das Nações Unidas para os Refugiados (ACNUR), existem apenas três possibilidades legais de proteção para aqueles que fugiram de seu país por causa de perseguição ou sérios perigos causados por um conflito: a integração social no lugar de refúgio; a repatriação voluntária no país de origem, desde que tenha se tornado seguro; ou o reassentamento (resettlement) em um país diferente daquele de primeiro refúgio, quando este não consegue fornecer ao refugiado a integração social no seu território ${ }^{3}$.

Na ausência de oportunidades adequadas de reassentamento em outros lugares, muitos dos milhões de refugiados presentes nos países de primeiro refúgio, onde sobrevivem em condições precárias, tentam atravessar de forma irregular outras fronteiras para entrar na Europa, arriscando suas vidas.

O não cumprimento da obrigação de proteção internacional por meio das soluções alternativas supracitadas - a digna inserção no país de primeiro refúgio ou o reassentamento em um país terceiro capaz de proporcionar oportunidades de integração - constitui, portanto, nestes últimos anos, uma das causas responsáveis por muitas mortes no mar (e, em relação aos refugiados sírios, certamente a principal delas).

É realmente uma responsabilidade pesada para a Europa - cuja disponibilidade para o reassentamento, até o momento, revelou-se bastante escassa - que insiste em oferecer refúgio somente a quem consegue alcançar de forma irregular as fronteiras do continente, como parece pressupor o próprio art. 78 do Tratado sobre o Funcionamento da União Europeia ${ }^{4}$.

3 Cf. DIRECTORATE-GENERAL FOR INTERNAL POLICIES, POLICY DEPARTMENT C. The Implementation of the Common European Asylum System, sobretudo p. 62.

4 "The guiding principle is that refugees and asylum seekers are not allowed to travel" (HEIJER, der Maarten, RIJPMA, Jorrit, SPIJKERBOER, Thomas. Coercion, Prohibition, and Great Eexpectations. The continuing failure of the Common European Asylum System). Sobre o tema da adaptação da disciplina de proteção à externalização das fronteiras, ver também: CASAS-CORTES, Maribel, COBARRUBIAS, Sebastian, PICKLES, John. Changing borders, rethinking sovereignty: towards a right to migrate. 
Um enorme "cemitério debaixo da lua" 5 foi assim se formando entre as duas margens do Mediterrâneo que não conseguem reatar entre elas uma parceria efetiva.

\section{Os "corredores humanitários" no contexto das ações da sociedade} civil que visam mudar o paradigma europeu do direito de refúgio

Os promotores dos "corredores humanitários", como já afirmamos, arcam com as despesas da viagem e do subsequente acolhimento, enquanto os respectivos governos emitem o visto de entrada somente depois de ter realizado os adequados controles de segurança.

Este modelo de cooperação entre o Estado e a sociedade civil, caracterizado pela assunção por parte desta última dos custos diretos do reassentamento, torna os "corredores humanitários" um modelo de mais fácil aceitação por parte dos governos. Tal modelo é replicável sempre que houver a disponibilidade da sociedade civil para realizá-lo, sem significativos custos econômicos e políticos pelas administrações públicas, uma vez que a responsabilidade pela entrada e acolhimento, pelo menos no primeiro ano, é totalmente das associações promotoras.

Trata-se de um modelo vantajoso, na perspectiva dos governantes, inclusive em termos de segurança, pois envolve a chegada de pessoas já identificadas e conhecidas.

\section{4. "Patrocinar" para evitar mortes no mar e enfrentar a imigração irregular}

Nascidos a partir de uma liberdade de ação solidária "graciosamente" concedida e delimitada pelos governos, os "corredores humanitários" carregam em si algumas ambiciosas linhas de mudança, seja em matéria de políticas públicas de refúgio e imigração, seja acerca do fortalecimento do papel que deveria ser reconhecido à sociedade civil, por exemplo, reintroduzindo, ainda que com características diferentes em relação ao passado, o processo de sponsorship.

Embora a Comissão Europeia os coloque entre os instrumentos atuais a serem incentivados a fim de garantir um melhor êxito aos programas de reassentamento dos solicitantes de refúgio, não há dúvida de que os patrocínios privados (sponsorship) constituem também uma modalidade possível de gerenciamento da entrada e do acolhimento de outras categorias de migrantes.

\footnotetext{
A expressão, extraída da obra de Bernanos, "I grandi cimiteri sotto la luna", é utilizada por Mons. Giancarlo PEREGO. Uomini e donne come noi, p. 8.
} 
O modelo de sponsorship, em outros termos, poderia também desenvolver uma função reguladora dos fluxos migratórios, pelo menos no que se refere às redes familiares e de amizade, típicas dos países de imigração em que vivem comunidades ainda não completamente desprendidas do cordão umbilical do país de origem. Nestes casos, um canal de imigração regular tiraria clientes, para além dos refugiados, das redes de tráfico de migrantes.

Traça-se, portanto, uma nova estratégia de acolhimento de alcance continental que, em vez de simplesmente contestar as políticas estatais e europeias, ou constatar as dificuldades enfrentadas pelos Estados membros na implementação de políticas e intervenções humanitárias mais corajosas, construa um inédito espaço de manobra para a sociedade civil europeia. Esta, a partir da iniciativa dos "corredores humanitários", pede, por sua vez, uma solidariedade limitadamente participativa dos governos, de modo a criar as premissas de consentimento ativo para futuras políticas públicas mais ousadas do que aquelas que hoje parecem determinadas por medos e humores eleitorais.

Muitas mais vidas poderiam, assim, ser protegidas e acompanhadas por caminhos virtuosos de inclusão social, modificando significativamente os números das políticas europeias de Procedimentos de Entrada Protegida (PEPs).

\section{As razões do nome}

O termo "corredores humanitários" não pertence ao léxico formal e técnico das organizações internacionais que lidam com o refúgio e a imigração, e tampouco aparecia, pelo menos até hoje, nas figuras do direito internacional humanitário para designar modalidades de resgate relacionadas à experiência em questão.

Fala-se, comumente, em "corredores" com respeito a rotas de trânsito seguras em áreas de combate, tanto para a transferência da população quanto para o transporte de ajudas.

Contudo, cabe destacar que também aqueles que conseguiram fugir das diversas áreas de conflitos armados precisam ser protegidos de perigos, muitas vezes mortais, como os naufrágios. Portanto, os promotores dos "corredores humanitários" consideraram que este deveria ser o nome da ação pela qual aos refugiados foi finalmente garantida a segurança da viagem até a chegada a um lugar de acolhimento estável e de inclusão social.

\section{Os "corredores humanitários" no âmbito dos Procedimentos de Entrada Protegida (PEPs)}

Quais são as peculiaridades dos "corredores humanitários" em relação aos diferentes Procedimentos de Entrada Protegida (PEPs)? Eles constituem, 
com certeza, uma alternativa possível - ainda que seja mais conveniente um regime de concorrência virtuosa - ao assim chamado asilo diplomático, que consiste em ter acesso aos procedimentos de análise do pedido de proteção internacional ainda na autoridade diplomática ou consular, com a posterior transferência para o país que assumiu a responsabilidade pela proteção.

Deve ser enfatizada a diferença, mas também algumas semelhanças, com as operações de transferência humanitária temporária, mediante as quais "um Estado-Membro aceita que um certo número de nacionais de países terceiros permaneçam no seu território por um período temporário, a fim de os proteger de crises humanitárias urgentes devido a eventos como, por exemplo, acontecimentos políticos ou conflitos" ${ }^{\prime \prime}$. Nessas ações, por vezes, a temporariedade permaneceu apenas como um propósito em decorrência da persistência da situação de crise humanitária. Em outras ocasiões, ao contrário, era motivada pela existência de um posterior projeto migratório, planejado e explicitado desde o início, de modo que a autorização de entrada e de permanência ocorreu por razões de trânsito ou de migração subsequente, gerida, às vezes, por Agências Internacionais.

Em geral, no que se refere ao modelo de reassentamento (resettlement), os programas temporários de admissão humanitária (com ou sem o uso de patrocinadores privados) diferem por uma maior simplicidade nos procedimentos, que são determinados pelas situações de emergência e vulnerabilidade a respeito de grupos de refugiados a quem - a não ser que posterior e individualmente solicitem proteção internacional - é concedida uma autorização de residência apenas temporária, de curta ou média duração, a ser renovada caso a situação de perigo ainda subsista no final do prazo indicado, eventualmente com a possibilidade que seja substituída por uma autorização de residência diferente, por exemplo, por razões de trabalho ou familiares.

Os "corredores humanitários" compartilham com esse tipo de ação a possibilidade de seus beneficiários não serem selecionados entre aqueles para quem o ACNUR oferece proteção internacional; por outro lado, diferenciam-se porque não presumem, embora não descartem, a natureza temporária da permanência, visando, antes, a melhor inclusão social possível em um cenário que, a curto prazo, inclusive como resultado de políticas nacionais de restrição da imigração por razões de trabalho, deveria também consentir a possibilidade de uma maior estabilidade daqueles que chegam à União Europeia em busca de refúgio.

Os "corredores humanitários", no entanto, diferem dos programas de reinstalação promovidos pela União Europeia nos Estados-Membros porque

${ }_{6}$ Cf. $<$ http://eur-lex.europa.eu/legal-content/PT/TXT/PDF/?uri=CELEX:32014R0516\&from=PT>. 
não exigem nenhuma contrapartida aos países de primeiro refúgio em termos de acordos de readmissão ou algo análogo.

Por fim, a última comparação entre os "corredores humanitários" e os outros possíveis PEPs diz respeito à sponsorship. Mesmo à luz das afirmações anteriores sobre os patrocínios privados, não há dúvida de que o projeto constitui uma modalidade particularmente estruturada, que se caracteriza pelo cuidado com que, mediante a constituição de uma coordenação local, foi valorizada a etapa de identificação dos beneficiários no território, etapa que não foi delegada a outros organismos. Ademais, a segunda característica importante dos "corredores humanitários" diz respeito às modalidades de acolhimento que visam à inclusão social no país de chegada. Uma preocupação por si própria inerente ao modelo de sponsorship, mas que, no caso em consideração, se realizou de uma forma que merece destaque.

\section{Qual o futuro dos vistos humanitários?}

O projeto de abertura de "corredores humanitários" foi implementado num contexto em que se acirrou na Europa o debate sobre a disciplina e a efetividade jurídica a serem reconhecidas, em termos gerais, ao "visto por razões humanitárias", referente ao art. 25 do Regulamento No. 810/20097. Recentemente, o Tribunal de Justiça da União Europeia, contrariando o parecer do advogado-geral, confirmou o caráter meramente "concessório", confiado à mera discricionariedade das administrações dos Estados deste tipo de visto ${ }^{8}$.

No entanto, mesmo não afirmando a obrigatoriedade de emitir um visto por razões humanitárias, nos parece necessário, hoje, expandir o seu uso em relação à amplitude e à intensidade das crises humanitárias, às possibilidades e/ ou prioridades dos Estados-Membros responsáveis pela emissão do visto, bem como aos pedidos recebidos de patrocinadores adequadamente selecionados. Somente criando rotas de acesso regulares, de fato, será possível enfrentar o tráfico ilegal de pessoas. E isso nos parece particularmente verdadeiro, tanto no tocante aos fluxos migratórios de seres humanos que buscam um lugar estável de refúgio, quanto para aqueles que, com outras motivações, almejam alcançar seus familiares que já residem na Europa, mas que as exigentes regras sobre o reagrupamento familiar e as ineficientes burocracias dos sistemas de estado civil não permitem chegar de forma regular.

\section{0 desafio da inclusão social}

Para onde levam os "corredores humanitários"? Felizmente não é para dentro de um quartel desativado ou dentro de um hotel quase abandonado,

\footnotetext{
Cf. <http://eur-lex.europa.eu/legal-content/PT/TXT/PDF/?uri=CELEX:32009R0810\&from=PT>.

8 Cf. Corte di giustizia dell'Unione europea. Grande sezione, 7 marzo 2017, C638/16.
} 
mas para muitas casas, lugares desejados e, portanto, eficazes e inclusivos do assim chamado "acolhimento difundido" (accoglienza diffusa). Com efeito, cabe às associações promotoras a responsabilidade do acolhimento e a assunção dos custos relacionados por um período de pelo menos um ano, no termo do qual, no entanto, não haverá interrupções automáticas do processo - como ocorre geralmente nos sistemas de recepção pública -, e sim a continuação do acompanhamento no percurso de inclusão social (com exceção, naturalmente, dos procedimentos de reunificação legal com membros da família residentes em outros países, especialmente Alemanha, França e Suécia).

Obviamente, nos casos em que o percurso da plena autonomia, mesmo almejado e procurado, não for alcançado, haverá um prolongamento do acolhimento até quando for necessário.

Não devem causar surpresa os baixos custos da rede de acolhimento desenvolvida pelos "corredores humanitários" em comparação com aqueles das instituições públicas. Isso pode ser facilmente explicado pela inegável vantagem econômica representada pelo envolvimento de redes locais de voluntários, muitos dos quais pertencentes às associações de voluntariado que não integram o grupo dos promotores dos "corredores" e, muitas vezes, que nem sequer têm como missão específica o acolhimento dos migrantes. Trata-se, ainda assim, de pessoas que cuidam de seus hóspedes sem limite de horário e nunca sozinhas.

A redução dos custos é com frequência provocada, também, pela disponibilização de moradias a título de comodato para fins de solidariedade tanto por parte de entidades públicas quanto por parte de pessoas dispostas a contribuir desta forma ao processo de acolhimento. O que, sem dúvida, deve ser interpretado também como uma resposta de adesão das comunidades locais ao apelo do Papa Francisco, dirigido inclusive às paróquias e às casas religiosas, para que os refugiados fossem acolhidos.

Merece um destaque o desafio assumido pelas associações promotoras de estabelecer um modelo de best practice de acolhimento, a custos acessíveis, em nível nacional, pelo menos em Itália, onde são evidentes os limites da qualidade do sistema de acolhimento, que está fortemente sobrecarregado pelo intenso fluxo de migrantes, que cresceu significativamente desde 2013, bem como pelo constante aumento dos pedidos de proteção internacional.

Os "corredores humanitários" se inserem no modelo de "acolhimento difundido" (accoglienza diffusa). Um modelo de não fácil realização por causa das complicações que, às vezes, podem surgir da espontaneidade das ofertas de acolhimento, especialmente levando em conta a fragilidade e, portanto, as possíveis dificuldades de inserção das pessoas recém-chegadas. Por estas razões, as numerosas disponibilidades para o acolhimento, que chegaram de 
todo o território nacional, foram examinadas por uma estrutura de coordenação que é responsável pela alocação das pessoas acolhidas e, portanto, pela escolha da inserção mais conveniente. Isso implica uma harmonização, pelo menos tendencial, das modalidades de acolhimento com referência à oferta de bens e serviços para os hóspedes; uma insistida ênfase na necessidade da aprendizagem do idioma italiano desde os primeiros dias (durante os quais, obviamente, é necessário o auxílio de mediadores que falem a língua nativa dos recém-chegados); a garantia de uma mobilidade adequada (meios de transporte, acessibilidade a centros urbanos e serviços públicos, etc.); a oferta de uma rede de sociabilidade apropriada por parte de voluntários que residem no território; a atenção para futuras oportunidades de inserção laboral; e, quanto mais cedo, o envolvimento em cursos de formação ou de atualização de conhecimentos profissionais, inclusive em estágios empresariais, sem ignorar a possibilidade real das pessoas acolhidas retomarem um percurso universitário que foi forçosamente interrompido ou adiado.

Ademais, no decurso da implementação do projeto, constatou-se um disseminado profissionalismo no acolhimento por parte das organizações voluntárias locais, já habituadas a formas análogas de planejamento e, portanto, muitas vezes mais preparadas operacionalmente do que algumas das entidades sociais de mais recente formação.

Precisamente porque energizado por motivações solidárias, conservadas em perspectivas existenciais e culturais em comunidades territoriais, ou pelo menos, em fragmentos de tais comunidades, o modelo de "corredores humanitários" não pode ser considerado como rival ou alternativo ao atual sistema público de acolhimento, mesmo porque não poderia assumir forçosamente seu tamanho. No entanto, pode constituir uma boa prática de referência e comparação.

Utilizando uma expressão bastante eficaz, a boa prática dos "corredores humanitários" foi definida como "adotiva" (adozionale) ${ }^{9}$. Essa expressão já foi utilizada há alguns anos pelo ministro da Integração, Andrea Riccardi, no que diz respeito ao modelo italiano de inclusão social dos migrantes nos territórios, em um país caracterizado em seu conjunto por uma tradição de welfare público menos sólida em relação a outros países europeus, mas dotado de uma cultura de partilha e, mais precisamente, de "adoção" mais desenvolvida que em outros lugares, o que constitui um recurso, desde que passe por um processo de consolidação, inclusive mediante uma sintonia institucional que pressupõe uma capacidade de gestão pública ${ }^{10}$.

9 Cf. IMPAGLIAZZO, Marco. Le vie dell'integrazione latina, p. 134.

${ }^{10}$ RICCARDI, Andrea. L'Europa dei migranti. Modelli d'integrazione, p. $103 \mathrm{ss}$. 
Não é por acaso que a própria Comissão Europeia pediu aos EstadosMembros que favoreçam os ingressos regulares mediante o patrocínio privado (sponsorship), porque "contribui também para sensibilizar as pessoas e apoiar os refugiados, proporcionando um ambiente mais acolhedor na medida em que as comunidades locais estão normalmente associadas ao processo"11.

O modelo "adotivo" não coincide, no entanto, com o voluntariado em si mesmo ou, mais genericamente, com a ideia do agir privado, mas diz respeito ao envolvimento de comunidades territoriais e, em particular, de seus núcleos familiares. Isso, em minha opinião, explica o fracasso de algumas experiências de acolhimento humanitário que, embora planejadas com a melhor das intenções, foram desenvolvidas em contextos locais inapropriados ou insuficientemente estimulados à inclusão social; explica, por outro lado, o êxito de experiências focadas na abordagem "adotiva" do acolhimento.

Nesta perspectiva, os termos opositivos inclusão/exclusão encontram uma declinação semântica particularmente evocativa nos termos adoção/ orfandade.

\section{Bibliografia}

CASAS-CORTES, Maribel; COBARRUBIAS, Sebastian; PICKLES, John. Changing borders, rethinking sovereignty: towards a right to migrate. REMHU, Revista Interdisciplinar da Mobilidade Humana, v. 23, n. 44, 2015, p. 4760. Disponível em: <http://www.scielo.br/pdf/remhu/v23n44/1980-8585REMHU-23-44-047.pdf >.

COLMAYER, Lucrezia; SIGNORINI, Michela. I corridoi umanitari, possibile alternativa di ingresso legale in Italia. Immigrazione.it., n. 281, 1 febbraio 2017.

DIRECTORATE-GENERAL FOR INTERNAL POLICIES, Policy Department C. The Implementation of the Common European Asylum System. Brussels: LIBE, 2016. HATHAWAY, James; GAMMELTOFT-HANSEN, Thomas. Non-Refoulement in a World of Cooperative Deterrence. Columbia Journal of Transnational Law, v. 52, n. 2, 2015, p. 235-284.

HEIJER, der Maarten; RIJPMA, Jorrit; SPIJKERBOER, Thomas. Coercion, Prohibition, and Great Eexpectations. The continuing failure of the Common European Asylum System. Common Market Law Review, v. 53, n. 3, 2016, p. 607-642. Disponível em: <https://papers.ssrn.com/sol3/papers.cfm?abstract_ $\mathrm{id}=2756709>$.

MORI, Paola. Le politiche relative all'asilo e all'immigrazione tra garanzie giurisdizionali e ragioni della politica. Il diritto dell'Unione europea, n. 1, 2016, p. 103-113.

${ }^{11}$ COMMISSIONE EUROPEA. Comunicazione del 6 aprile 2016, COM (2016) 197 final. Riformare il sistema europeo comune di asilo e potenziare le vie legali di accesso all'Europa, p. 17. Disponível em: <https://ec.europa.eu/transparency/regdoc/rep/1/2016/PT/1-2016-197-PT-F1-1.PDF>. 
MOROZZO DELLA ROCCA, Paolo. I due protocolli d'intesa sui "corridoi umanitari" tra alcuni enti di ispirazione religiosa ed il loro possibile impatto sulle politiche di asilo e immigrazione. Diritto immigrazione e cittadinanza, n. 1, 2017. Disponível em: <www.dirittoimmigrazionecittadinanza.it>.

SOSSAI, Mirko. Canali di ingresso legale e sicuro dei migranti in Europa: il modello dei "corridoi umanitari". In CURI, Umberto (a cura di). Vergogna ed esclusione. L'Europa di fronte alla sfida dell'emigrazione. Roma: Castelvecchi, 2017, p. 75-89.

TREVISANUT, Seline. The Principle of Non-Refoulement And the DeTerritorialization of Border Control at Sea. Leiden Journal of International Law, v. 27, n. 3, 2014, p. 661-675.

YAHVAOUI KRIVENKO, Ekaterina. Hospitality and Sovereignty: What Can We Learn From the Canadian Private Sponsorship of Refugees Program? International Journal of Refugee Law, v. 24, n. 3, 2012, p. 579-602.

Recebido para publicação em 28.08.2017

Aceito para publicação em 09.10.2017

Received for publication in August 28 ${ }^{\text {th }}, 2017$

Accepted for publication in October 09 ${ }^{\text {th }}, 2017$

ISSN impresso 1980-8585

ISSN eletrônico 2237-9843

http://dx.doi.org/10.1590/1980-85852503880005104 